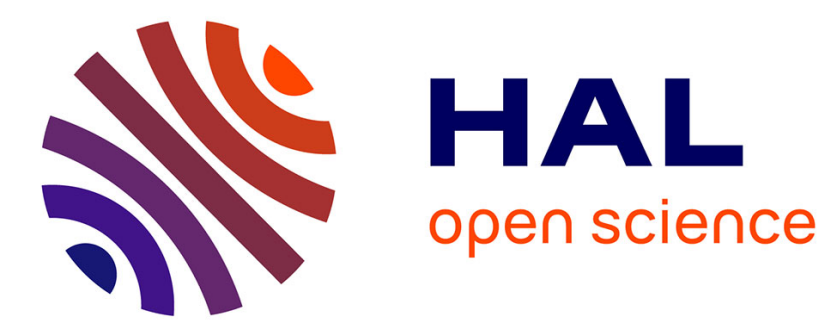

\title{
High-Resolution NMR of Folded Proteins in Hyperpolarized Physiological Solvents
}

Pavel Kadeřávek, Fabien Ferrage, Geoffrey Bodenhausen, Dennis Kurzbach

\section{To cite this version:}

Pavel Kadeřávek, Fabien Ferrage, Geoffrey Bodenhausen, Dennis Kurzbach. High-Resolution NMR of Folded Proteins in Hyperpolarized Physiological Solvents. Chemistry - A European Journal, 2018, 24 (51), pp.13418-13423. 10.1002/chem.201802885 . hal-01955712

\section{HAL Id: hal-01955712 https://hal.sorbonne-universite.fr/hal-01955712}

Submitted on 14 Dec 2018

HAL is a multi-disciplinary open access archive for the deposit and dissemination of scientific research documents, whether they are published or not. The documents may come from teaching and research institutions in France or abroad, or from public or private research centers.
L'archive ouverte pluridisciplinaire HAL, est destinée au dépôt et à la diffusion de documents scientifiques de niveau recherche, publiés ou non, émanant des établissements d'enseignement et de recherche français ou étrangers, des laboratoires publics ou privés. 


\title{
High-Resolution NMR of Folded Proteins in Hyperpolarized Phys- iological Solvents
}

\author{
Pavel Kadeřávek ${ }^{[a], *}$, Fabien Ferrage ${ }^{[b]}$, Geoffrey Bodenhausen ${ }^{[b]}$, Dennis Kurzbach ${ }^{[b], *}$
}

\begin{abstract}
We report hyperpolarized 2D exchange spectroscopy (HYPEX) to obtain high-resolution nuclear magnetic resonance (NMR) spectra of folded proteins under near-physiological conditions. The technique is based on hyperpolarized water, which is prepared by dissolution dynamic nuclear polarization and mixed in-situ in an NMR spectrometer with a protein in a physiological saline buffer at body temperature. We show that rapid exchange of labile protons with the hyperpolarized solvent, combined with cross-relaxation effects (NOEs), leads to boosted signal intensities for many amide ${ }^{1} \mathrm{H}-{ }^{15} \mathrm{~N}$ resonances in the protein ubiquitin. As the introduction of hyperpolarization to the target protein is mediated via the solvent, the method is applicable to a broad spectrum of target molecules.
\end{abstract}

Protein structures and functions are frequently determined by environmental conditions ${ }^{[1]}$. This is reflected in properties such as multi-functionality and gene sharing ${ }^{[2]}, \mathrm{pH}$ - and temperature-sensitivity ${ }^{[3]}$, or concentration-dependent turnover ${ }^{[4]}$. It is therefore important to investigate proteins under physiological conditions to obtain information about their native states. Solution-state nuclear magnetic resonance (NMR) is a versatile method to study proteins with atomic resolution. However, to improve the sensitivity and sample stability, NMR experiments are usually carried out under non-physiological conditions (e.g., low $\mathrm{pH}$ and low temperatures). To overcome this drawback, we show how dissolution dynamic nuclear polarization (D-DNP) can selectively enhance NMR signals of many residues in proteins under near-physiological conditions. We demonstrate the method for ${ }^{15} \mathrm{~N}$-enriched Ubiquitin (Ubq), a globular protein, yielding up to ca. 70-fold enhanced NMR signals for a subset of residues, in comparison to a conventional thermal equilibrium NMR spectrum, translating into a reduction in experimental time from hours to seconds.

Signal enhancement through hyperpolarized solvents has recently been illustrated for intrinsically disordered proteins (IDPs) by Szekely et al. ${ }^{[5]}$ and by Kurzbach et al. ${ }^{[6]}$, albeit with somewhat limited resolution. Here, we expand this approach to high-resolution NMR of folded proteins, for which hyperpolarization is more challenging but also more informative, as - in contrast to IDPs - the solvent-mediated enhancement factor is strongly dependent on the position of a residue in the secondary and tertiary structures of the protein.

Hyperpolarized exchange (HYPEX) NMR is possible thanks

[a] Dr. Pavel Kaderávek

CEITEC-Central European Institute of Technology, Masaryk University, Kamenice 5, CZ-625 00 Brno, Czech Republic

[b] Dr. Pavel Kadeřávek, Prof. Fabien Ferrage, Prof. Geoffrey Bodenhausen, Dr. Dennis Kurzbach

Laboratoire des biomolécules, LBM, Département de chimie, École normale supérieure, PSL University, Sorbonne Université, CNRS, 75005 Paris,

Email: Pavel.Kaderavek@ceitec.muni.cz; Dennis.Kurzbach@ens.fr to the unique combination of an $800 \mathrm{MHz}$ spectrometer and a DDNP prototype connected via a magnetic tunnel. Our experimental strategy is the following: $\mathrm{H}_{2} \mathrm{O}$ containing $17.5 \mathrm{mM}$ TEM$\mathrm{POL}$ radicals is (i) mixed with $15 \% \mathrm{v} / \mathrm{v}$ glycerol, ${ }^{[6]}$ and (ii) hyperpolarized at $T_{\mathrm{DNP}}=1.2 \mathrm{~K}$ in a magnetic field $B_{\mathrm{DNP}}=6.7 \mathrm{~T}$, yielding proton polarization levels $P\left({ }^{1} \mathrm{H}\right)>80 \%$. Subsequently, the sample is dissolved by a burst of superheated $\mathrm{D}_{2} \mathrm{O}\left(180{ }^{\circ} \mathrm{C}\right.$, $1 \mathrm{MPa}$ ) and propelled within $1.3 \mathrm{~s}$ by helium gas at $0.7 \mathrm{MPa}$ through a ca. $5 \mathrm{~m}$ long "magnetic tunnel" ${ }^{[7]}$ to an $800 \mathrm{MHz}$ NMR spectrometer $\left(B_{0}=18.8 \mathrm{~T}\right)$. After dissolution, all solvent protons can be assumed to be present in the form of HDO, since the final solvent mixture only contains $2 \% \mathrm{H}_{2} \mathrm{O}$.

In the spectrometer, a $5 \mathrm{~mm}$ thick-wall NMR sample tube is inserted, containing a $2.1 \mathrm{mM}$ Ubq solution at $\mathrm{pH} 7.4$ in a deuterated physiological saline buffer at body temperature $T=37^{\circ} \mathrm{C}$ $(310 \mathrm{~K})$. The hyperpolarized solvent is mixed in-situ $(1: 1 \mathrm{v} / \mathrm{v})$ with the Ubq solution that is waiting in the NMR spectrometer. Finally, a $\left({ }^{1} \mathrm{H}-{ }^{15} \mathrm{~N}\right)$ correlation spectrum is recorded using the SOFAST-HMQC technique ${ }^{[8]}$. The detection time window is determined by the lifetime of the proton hyperpolarization in $\mathrm{HDO}$, which has been determined to be $T_{1}\left({ }^{1} \mathrm{H}\right)=6.5 \pm 0.1 \mathrm{~s}$ at $310 \mathrm{~K}$ and $18.8 \mathrm{~T}$.

The $98 \%$ solvent deuteration represents a compromise between the hyperpolarization lifetime, which increases with the degree of deuteration but reduces signal enhancements, and the proton concentration, which obviously decreases with deuteration and boosts signal enhancements. The final protein concentration was ca. $1.05 \mathrm{mM}$. The TEMPOL concentration after dissolution and mixing was $0.3 \mathrm{mM}$.

Rapid mixing of hyperpolarized HDO with the protein solution leads to a selective transfer of polarization ${ }^{[9]}$ from the solvent to labile protons, thus introducing hyperpolarized nuclei into the protein, resulting in a boost of signal intensities as shown by comparison of the intensities of ${ }^{1} \mathrm{H}^{\mathrm{N}}$ signals in conventional HSQC (orange) and HYPEX-boosted (blue) spectra (Fig. 1a).

The 2D HYPEX ${ }^{1} \mathrm{H}-{ }^{15} \mathrm{~N}$ correlation spectrum (Fig. 1b, red) displays only a subset of cross-peaks when compared to a conventional HSQC spectrum in thermal equilibrium (Fig. 1b, black). These are mostly located in the first two $\beta$-strands and in the $\beta 1-\beta 2$ turn, the flexible C-terminal tail of Ubq, as well as in flexible loops housing amide protons that rapidly exchange with hyperpolarized solvent protons.

To quantify the increase of signals due to hyperpolarization in comparison to state-of-the-art NMR techniques, we introduce the HYPEX/HSQC ratio $\varepsilon^{*}$ i of the ${ }^{1} \mathrm{H}^{\mathrm{N}}{ }_{-}{ }^{15} \mathrm{~N}$ cross-peak signal of the $i^{\text {th }}$ residue, which is defined as the ratio of the signal-to-noise ratios (SNR) weighted by the number of scans per $t_{1}$ increment $\left(N_{\text {HSQC }}\right.$ and $\left.N_{\text {HYPEX }}\right)$ :

$$
\varepsilon^{*}{ }_{i}=\left(S N R_{\text {HYPEX }}^{i_{\text {H }}} / S N R_{\text {HSQC }}^{i}\right) \cdot\left(N_{\text {HSQC }} / N_{\text {HYPEX }}\right)^{1 / 2}
$$



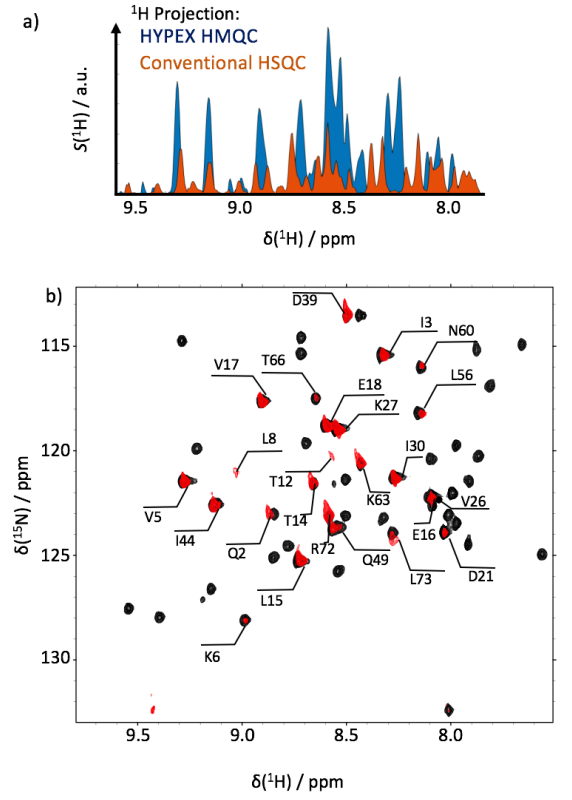
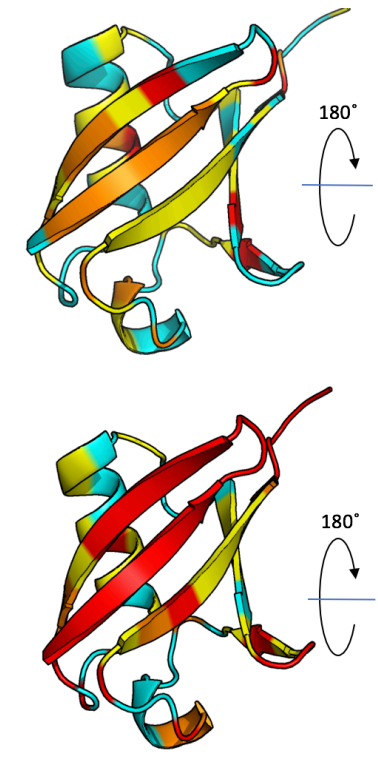
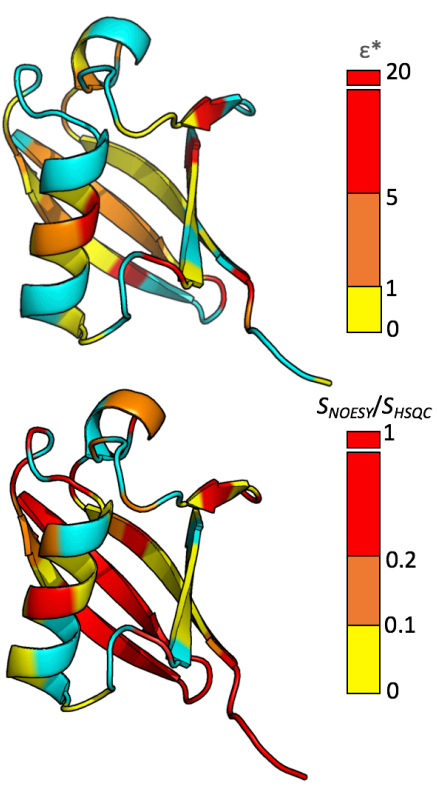

Figure 1. a) Projections onto the ' $\mathrm{H}$ dimensions of the HYPEX SOFAST-HMQC (blue) in a buffer containing $2 \% \mathrm{H}_{2} \mathrm{O}$ and $98 \% \mathrm{D}_{2} \mathrm{O}$ and of a conventional HSQC spectrum (red) in a buffer containing $90 \% \mathrm{H}_{2} \mathrm{O}$ and $10 \% \mathrm{D}_{2} \mathrm{O}$ indicating the signal enhancements obtained via hyperpolarization (scaled to take into account the number of averaged signals and the receiver gain). The HSQC method has been chosen as "gold standard" for comparison as it is less prone to spurious effects of solvent exchange as the HMQC method (see text). b) ${ }^{1} \mathrm{H}-{ }^{15} \mathrm{~N}$ correlation spectrum of Ubq recorded with the HSQC method, detected without DNP, when the proton polarization is in thermal equilibrium at $37^{\circ} \mathrm{C}$ (black, average over 16 scans, $200 t_{1}$ increments) and selectively boosted by SOFASTHMQC-detected HYPEX (red, 1 scan, $64 t_{1}$ increments). The assignments are given only for enhanced residues. c) "Heat map" based on the X-ray diffraction crystal structure of Ubq (PDB code $1 \mathrm{UBQ}$ ), where residues boosted by HYPEX with weak, medium and strong ratios $\varepsilon^{*}$ of signal intensities in HYPEX with respect to a conventional HSQC are highlighted in yellow, orange and red. d) "Heat map" of Ubq indicating signal intensities in a water-selective NOESY-HSQC experiment where weak, medium and strong selective NOESY signals $S_{N O E}$ relative to a signal $S_{\text {ref }}$ in a conventional HSQC are highlighted in yellow, orange and red. The water-selective NOE signal intensity gives a measure of the strength of protein-water interactions. Enhanced regions and regions that feature strong water-selective NOE signals in c) and d) are correlated (see text).

where the reference HSQC signal was obtained at thermal equilibrium with the gradient selective, sensitivity-enhanced method ${ }^{[10]}$ using the same sample volume inside the NMR coil, protein concentration, $\mathrm{pH}$ and temperature, but in a saline buffer containing $90 \% \mathrm{H}_{2} \mathrm{O}$ and $10 \% \mathrm{D}_{2} \mathrm{O}$. For the case at hand, $N_{\text {HSQC }} / N_{\text {HYPEX }}=8 / 1$.

In contrast, we define the conventional enhancement factor $\varepsilon_{\mathrm{i}}$ as

$$
\varepsilon_{\mathrm{i}}=\left(S N R_{\text {HYPEX }}^{\mathrm{i}} / S N R_{\mathrm{TE}}^{\mathrm{i}}\right) \cdot\left(N_{\mathrm{TE}} / N_{\text {HYPEX }}\right)^{1 / 2}
$$

where TE indicates that a SOFAST-HMQC (as used for HYPEX) spectrum in thermal equilibrium was used as reference after the hyperpolarization had decayed completely. The standard enhancement factor $\varepsilon$ is thus defined as the ratio of absolute signal intensities $S_{i}$ in a HYPEX experiment and in a similar SOFAST HMQC obtained in thermal equilibrium. As "gold standard" reference we yet chose the HSQC method (eq. 1) as it yields the most intense spectrum that can be obtained under our experimental conditions without hyperpolarization. Since HSQC relies on the evolution of in-phase and anti-phase single quantum coherences in the $t_{1}$ evolution interval, it is less affected by proton exchange, unlike HMQC where heteronuclear doublequantum coherences constantly decay through proton exchange - the latter being fostered at $\mathrm{pH} 7.4 .^{[11]}$

We acquired the HYPEX spectrum in one scan for each of $64 t_{1}$ increments spaced by delays of $0.3 \mathrm{~s}$, while the reference HSQC was measured with 8 scans for each of $200 t_{1}$ increments with a recovery delay of $2 \mathrm{~s}$. The ratio $\varepsilon^{*}$ thus compares the HYPEX signal intensity with the best signal we could obtain with conventional NMR, irrespective of the number of increments, different interscan delay, excitation pulse angels and the degree of sample deuteration.

The HYPEX/HSQC ratios $\varepsilon^{*}$ (Eq. 1) vary greatly along the sequence of Ubq (Figs. 1c and 2a). For some rapidly exchanging residues in loops and turns, as well as in the $\beta$-sheet of Ubq, HYPEX/HSQC ratios up to $\varepsilon^{*}{ }_{i}=13$ could be observed in our experiments (Table 1, Fig. 2a) despite a 168-fold reduction of experimental time. Note that signal enhancements in structural elements that appear rigidly folded in the crystal structure of Ubq, such as the $\beta$-sheet,${ }^{[3 c]}$ might feature structural fluctuations under near-physiological conditions such as rapid opening and closing of the $\beta$-sheet. Such fluctuations might increase solvent exposure of residues buried in the protein's core and facilitate the transfer of hyperpolarization from the buffer.

The HYPEX spectrum was detected in $19 \mathrm{~s}$, while the reference HSQC needed $3200 \mathrm{~s}$. By contrast, residues involved in the $\alpha$-helix showed small values of HYPEX/HSQC ratios $\varepsilon^{*}$ and many HYPEX signals are below the detection threshold. The different numbers of $t_{1}$ increments, different recovery delays, and different $\mathrm{H}_{2} \mathrm{O} / \mathrm{D}_{2} \mathrm{O}$ ratios are not considered in the definition of $\varepsilon^{*}$, so that large HYPEX/HSQC ratios $\varepsilon^{*}$ translate into much larger enhancement factors $\varepsilon$ that are commonly used (eq. 2). The enhancements reach $\varepsilon>60$. However, signals of many residues in the reference HMQC experiment were too weak to be detect- 
ed in thermal equilibrium and are only visible via HYPEX. The enhancement factors $\varepsilon$ of the detectable residues in the reference SOFAST HMQC experiment are listed in Table 1. Note that the low $\mathrm{H}_{2} \mathrm{O} / \mathrm{D}_{2} \mathrm{O}$ ratio $2 \%$ used for HYPEX experiments leads to a 45-fold loss in signal intensity compared to the $\mathrm{H}_{2} \mathrm{O} / \mathrm{D}_{2} \mathrm{O}$ ratio of $90 \%$ normally used in thermal equilibrium. Interestingly, when inspecting Table 1 , we find values for $\varepsilon / \varepsilon^{*}$ significantly different from 45 . This points towards the presence of additional processes next to proton exchange that may contribute to the sensitivity of our experiments.

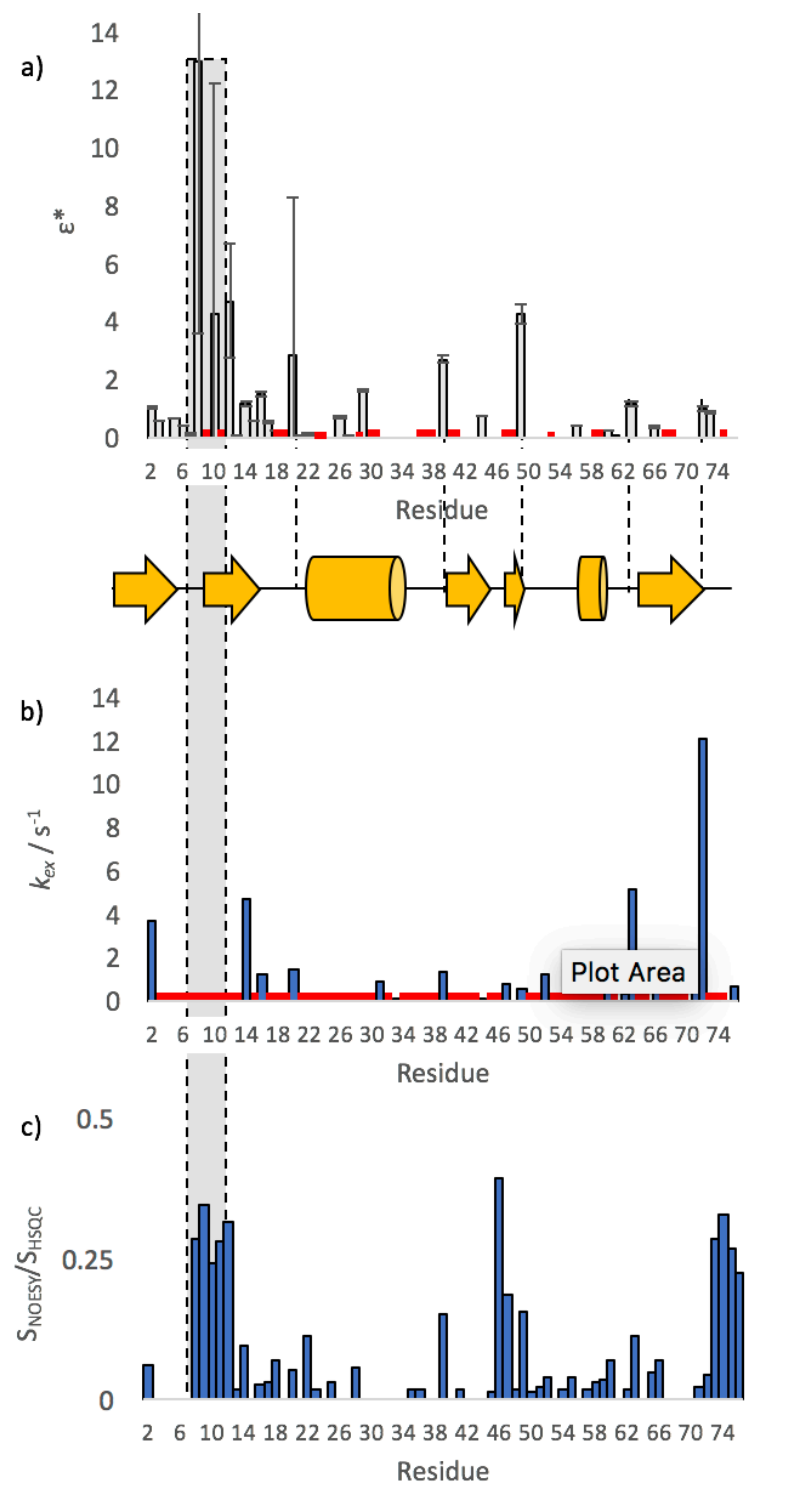

Figure 2. a) Residue-specific HYPEX/HSQC ratios $\varepsilon^{*}{ }_{i}$ (see eq.1) of backbone amide protons $\mathrm{H}^{\mathrm{N}}$ in Ubq. Residues with strong HYPEX/HSQC ratios are mainly situated in loop regions and in the main $\beta$-sheet. Residues that could not be detected in either HYPEX or reference experiment are indicated in red. b) Residue-specific ${ }^{1} \mathrm{H}^{\mathrm{N}}$ exchange rates with the solvent, taken from RelaxEXSY at $\mathrm{pH} 7.4$ and $37^{\circ} \mathrm{C}$. The red residues could not be analyzed due to unfavorable NMR conditions and fast exchange. c) Residue-specific selective water-NOESY enhancements $S_{\text {NOESY }} / S_{\text {ref }}$ at $\mathrm{pH} 7.4$ and $37^{\circ} \mathrm{C}$. A high value indicates fast proton exchange with the solvent or an efficient NOE path from hyperpolarized protons to the detected ${ }^{1} \mathrm{H}^{\mathrm{N}}$ atoms. The grey strip highlights residues in the $\beta 1-\beta 2$ turn that interact strongly with the aqueous surrounding.
Hence, to rationalize the observed signal enhancements $\varepsilon$, we carried out water-selective nuclear Overhauser enhancement spectroscopy (NOESY) experiments, where signals arise from a combination of cross-relaxation and chemical exchange with water protons, the two mechanisms that are expected to contribute to the transfer of hyperpolarization from the solvent to the protein in HYPEX experiments. We used a method adapted from Stonehouse et al. ${ }^{[12]}$ After selective presaturation of the protein protons (not the water or the $\alpha$-proton resonances; see Materials and Methods for details), we allow the polarization of the surrounding water to migrate to the protein during a mixing period $\tau_{\mathrm{m}}$ before a conventional HSQC sequence. This experiment was performed with conventional NMR at $10 \%$ solvent deuteration.

Table 1. Enhancement factors $\varepsilon$ and HYPEX/HSQC ratios $\varepsilon^{*}$ for residues in Ubq that are observable by D-DNP. For some residues denoted n/a, $\varepsilon$ could not be determined due to weak signal intensities in the reference spectrum.

\begin{tabular}{cccc}
\hline Residue & $\varepsilon$ & $\varepsilon^{*}$ & $\varepsilon / \varepsilon^{*}$ \\
\hline 2 & $12.8 \pm 0.5$ & $1.1 \pm 0.1$ & 11.6 \\
3 & $\mathrm{n} / \mathrm{a}$ & $0.6 \pm 0.1$ & $\mathrm{n} / \mathrm{a}$ \\
5 & $\mathrm{n} / \mathrm{a}$ & $0.6 \pm 0.1$ & $\mathrm{n} / \mathrm{a}$ \\
6 & $\mathrm{n} / \mathrm{a}$ & $0.4 \pm 0.1$ & $\mathrm{n} / \mathrm{a}$ \\
7 & $\mathrm{n} / \mathrm{a}$ & $0.1 \pm 0.1$ & $\mathrm{n} / \mathrm{a}$ \\
8 & $66.1 \pm 17.0$ & $13.0 \pm 9.4$ & 5.1 \\
10 & $\mathrm{n} / \mathrm{a}$ & $4.3 \pm 4.0$ & $\mathrm{n} / \mathrm{a}$ \\
12 & $\mathrm{n} / \mathrm{a}$ & $4.7 \pm 1.9$ & $\mathrm{n} / \mathrm{a}$ \\
14 & $9.9 \pm 0.25$ & $1.2 \pm 0.1$ & 8.4 \\
16 & $\mathrm{n} / \mathrm{a}$ & $1.5 \pm 0.1$ & $\mathrm{n} / \mathrm{a}$ \\
18 & $12.2 \pm 1.2$ & $0.3 \pm 0.1$ & 48.8 \\
20 & $\mathrm{n} / \mathrm{a}$ & $2.8 \pm 1.9$ & $\mathrm{n} / \mathrm{a}$ \\
22 & $19.1 \pm 15.0$ & $0.1 \pm 0.1$ & 191.0 \\
26 & $25.0 \pm 0.5$ & $0.7 \pm 0.1$ & 35.7 \\
27 & $\mathrm{n} / \mathrm{a}$ & $0.1 \pm 0.1$ & $\mathrm{n} / \mathrm{a}$ \\
39 & $25.4 \pm 0.9$ & $2.7 \pm 0.2$ & 9.3 \\
44 & $11.3 \pm 2.2$ & $0.1 \pm 0.1$ & 113.0 \\
49 & $47.0 \pm 2.8$ & $4.3 \pm 0.4$ & 11.0 \\
56 & $\mathrm{n} / \mathrm{a}$ & $0.4 \pm 0.1$ & $\mathrm{n} / \mathrm{a}$ \\
60 & $2.0 \pm 0.1$ & $0.2 \pm 0.1$ & 10.0 \\
63 & $13.1 \pm 0.5$ & $1.2 \pm 0.1$ & 11.0 \\
66 & $0.4 \pm 0.1$ & $0.3 \pm 0.1$ & 1.3 \\
72 & $\mathrm{n} / \mathrm{a}$ & $1.0 \pm 0.1$ & $\mathrm{n} / \mathrm{a}$ \\
73 & $\mathrm{n} / \mathrm{a}$ & $0.9 \pm 0.1$ & $\mathrm{n} / \mathrm{a}$ \\
& & & \\
& & & \\
& & &
\end{tabular}

Figure 2c shows water-selective NOESY enhancements in comparison to a conventional HSQC spectrum (denoted as the intensity ratio $S_{\text {NOESY }} / S_{H S Q C}$; cf. Fig. 1d) measured at $\mathrm{pH} 7.4$ and $37^{\circ} \mathrm{C}$ and a mixing time corresponding to the HYPEX recovery delay of $0.3 \mathrm{~s}$. Residues 6 to 13 in the $\beta 1-\beta 2$ turn (grey strip) exhibit very high intensities $S_{\text {NOESY }}$ corresponding to a strong interaction with the surrounding water. Residue 8 , which shows especially high $\varepsilon$ in Fig. 2a, also shows intense water-selective NOESY signals (Fig. 2c). Indeed, this residue is barely detectable by conventional NMR at $\mathrm{pH} 7.4$ and $37^{\circ} \mathrm{C}$, but leads to clear signal in HYPEX spectra. In contrast, residue 9 that belongs to the $\beta 1-\beta 2$ turn cannot be detected, not even with $\operatorname{HYPEX}\left(\varepsilon^{*}=\varepsilon\right.$ $=0$ in Fig. 2a). 

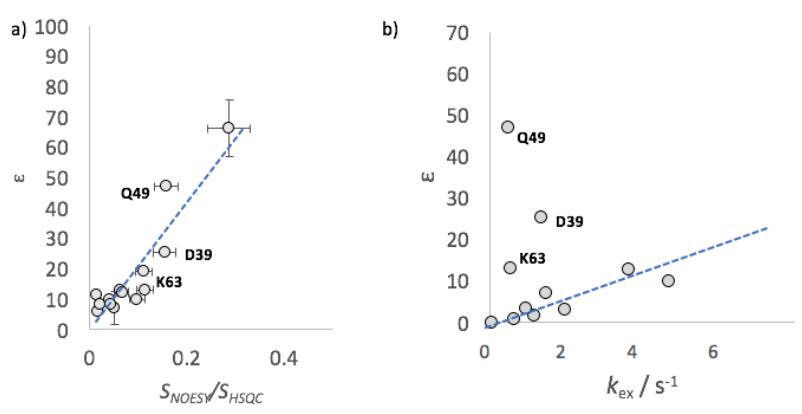

Figure 3. a) HYPEX/HSQC ratios $\varepsilon$ vs. water-selective NOESY signal intensities $S_{\text {NOESY }} / S_{H S Q C}$. The dashed line indicates a linear fit with an intercept at the origin $\varepsilon=S_{\text {NOESY }} / S_{\text {HYPEX }}=0$. Error margins of the linear fits are indicated in blue. b) HYPEX/HSQC ratios $\varepsilon$ vs amide proton exchange rates $k_{\mathrm{ex}}$ measured by Relax-EXSY. The dashed line indicates a linear fit with an intercept at the origin $\varepsilon^{*}=k_{\mathrm{ex}}=0$. Residues D39, Q49 and K63 appear as outliers in (b), in contrast to (a).

Signal intensities $S_{\text {NOESY }}$ in water-selective NOESY experiments correlate well with HYPEX/HSQC ratios $\varepsilon^{*}$ as shown in Fig. 3a. This confirms that elevated enhancements $\varepsilon$ result from a combination of NOEs and solvent exchange ${ }^{[13]}$.

Note that a few residues that show enhanced signal intensities in water-selective NOESY experiments do not appear as enhanced signals in HYPEX spectra (cf. Figs. 1 and 2). The SOFAST HMQC sequence employed here precludes detection of residues below $8 \mathrm{ppm}$ that are close to the water resonance, which is very broad (if detected) due to radiation damping resulting from hyperpolarization. ${ }^{[14]}$ No peaks at lower frequencies can be observed in HYPEX spectra. In principle, techniques that employ hard pulses on protons, such as the ALSOFAST $H S Q C^{[15]}$, might overcome this limitation, but in our hands hard pulses always led to severe radiation damping effects ${ }^{[14]}$.

Additionally, another factor causes signal loss: As explained above, when the amide proton exchange rates are too fast, rapid decay of heteronuclear double-quantum coherences in SOFAST HMQC experiments prevents the enhancements of some residues. This explains that many residues in the $\beta 1-\beta 2$ turn show high signal intensities $S_{\text {NOESY, }}$ but are undetectable in HYPEX HMQC spectra.

To disentangle exchange contributions from NOE effects, we determined the ${ }^{1} \mathrm{H}^{\mathrm{N}}$ amide/HDO proton exchange rates. We employed the Relax-EXSY experiment ${ }^{[16]}$ (Fig. 2b), where one fits the relaxation and exchange rates to the decays of longitudinal ${ }^{15} \mathrm{~N}$ magnetization as a function of the degree of deuteration of the solvent (for details see Materials and Methods). Note that this approach is very precise, though limited to rates that are comparable to the ${ }^{15} \mathrm{~N}$ longitudinal relaxation rate: $k_{\mathrm{ex}} \sim R_{1}\left({ }^{15} \mathrm{~N}\right)=$ $1 / T_{1}\left({ }^{15} \mathrm{~N}\right)$. For our experimental conditions $R_{1}\left({ }^{15} \mathrm{~N}\right) \sim 2 \mathrm{~s}^{-1}$ so that rates in fast-exchanging residues and some very slowly exchanging residues (like in the $\alpha$-helix) could not be determined (see Supporting Information for a list of $R_{1}\left({ }^{15} \mathrm{~N}\right)$ ).

Many enhancement factors $\varepsilon$ correlate well with proton exchange rates $k_{\mathrm{ex}}$ (Fig. $3 \mathrm{~b}$ ) suggesting that the exchange of amide protons with the solvent is the dominant mechanism of signal enhancement. For residues with high HYPEX or HSQC ratios $\varepsilon$ or $\varepsilon^{*}>2$, no exchange rates could be measured by Relaxexchange spectroscopy (EXSY) NMR. Some residues, such as D39, Q49 and K63, show surprisingly high $\varepsilon>10$ despite low exchange rates $k_{\mathrm{ex}}<1.6 \mathrm{~s}^{-1}$, while they correlate well with the signal intensities in water-selective NOESY, which indicates contributions beyond direct chemical exchange such as intraand/or intermolecular NOEs influencing $\varepsilon$. Therefore, the three outliers in Fig. $3 b$ show high $\varepsilon$ despite their low exchange rates, but their enhancements correlate well with the NOESY signal intensities (Fig. 3a) suggesting that NOEs, either direct or exchange relayed, contribute positively to the signal enhancement. This is in line with the observations of Hilty and co-workers ${ }^{[17]}$ who showed that intra-molecular NOEs from hyperpolarized protons can contribute to the enhancement of neighboring nuclei. Note that NOEs from short-lived hydration water molecules are expected to appear as negative contributions to signals in a ${ }^{1} \mathrm{H}$ ${ }^{15} \mathrm{~N} \mathrm{HSQC/HMQC}$, for which we yet have no evidence. ${ }^{[18]}$

Nucci et al. ${ }^{[13]}$ reported that hydration water near the $\beta$ sheet of Ubq can feature rather long life times (albeit in inverse micelles, which differ from our experimental conditions), thus increasing the probability of intermolecular NOEs from $\mathrm{HDO}$ to ${ }^{1} \mathrm{H}^{\mathrm{N}}$, which could boost HYPEX signals. Interestingly, some residues that are embedded in the $\beta$ sheet seem to be more strongly hyperpolarized than residues in loop and helix regions, again pointing to the importance of NOE contributions. An indirect mechanism might contribute that involves exchange of hyperpolarized water with labile protons (possibly $\mathrm{OH}$ or $\mathrm{NH}$ groups on side chains or backbone) followed by intramolecular NOEs to nearby amides. The direct and indirect NOE pathways cannot be distinguished with the techniques employed here. Yet, many residues that feature high enhancements are located next to amino acids with labile side chain protons (e.g., L8 next to T7, and Q49 next to K47) hinting at exchange-relayed NOEs.

The effect of NOEs may furthermore be boosted by constant replenishing through fast exchange of labile protons or water molecules in the first solvation shell. This probably explains the significant enhancement of residues that are buried in the hydrophobic core, which feature exchange rates below the detection threshold and yet show high enhancements.

In conclusion, the HYPEX approach to NMR of folded proteins has several advantages. On the one hand, it reduces detection times from minutes or hours to seconds, which may allow one to study proteins that degrade too fast for conventional NMR, even under physiological conditions.

On the other hand, HYPEX-detected NMR can provide a set of enhanced signals that can serve as probes to study biomolecular interactions.

\section{Experimental Section}

$D$-DNP A volume of $200 \mu \mathrm{L}$ of a $15 \mathrm{mM}$ TEMPOL solution in a $0: 85: 0.15 \mathrm{v} / \mathrm{v}$ mixture of water and glycerol was vitrified in liquid helium. The glassy sample was positively hyperpolarized for $3 \mathrm{~h}$ at $1.2 \mathrm{~K}$ in a magnetic field of $6.7 \mathrm{~T}$ by saturation of the EPR 
spectrum at $187.7 \mathrm{GHz}{ }^{[6]}$. Dissolution was achieved with a burst of $5 \mathrm{~mL} \mathrm{D}_{2} \mathrm{O}$ at $180{ }^{\circ} \mathrm{C}(453 \mathrm{~K})$ under $1 \mathrm{MPa}$. The sample was subsequently propelled to the detection NMR spectrometer within $1.3 \mathrm{~s}$ with $\mathrm{He}$ gas under $0.7 \mathrm{MPa}$. Mixing with the target protein solution and settling of turbulences was completed after $3 \mathrm{~s}$.

NMR Spectroscopy A single $\left({ }^{1} \mathrm{H},{ }^{15} \mathrm{~N}\right)$ SOFAST HMQC spectrum was detected within $19 \mathrm{~s}$ with 32 real and 32 imaginary $t_{1}$ points with increments $\Delta t_{1}=411 \mu \mathrm{s}$ at a recovery delay of $0.3 \mathrm{~s}$ and an acquisition time of $0.1 \mathrm{~s}$, using selective ${ }^{1} \mathrm{H}^{\mathrm{N}}$ excitation pulses PC90 (3.6 ms for $120^{\circ}$ ) and inversion RSNOB (1 ms for $180^{\circ}$ ) with a carrier frequency at $9.5 \mathrm{ppm}$ to avoid perturbing the water resonance, which could lead to radiation damping effects. The ${ }^{15} \mathrm{~N}$ carrier frequency was set at $118 \mathrm{ppm}$ and the spectral width was $2.4 \mathrm{kHz}$ (30 ppm). The spectra were processed using NMRPipe ${ }^{[19]}$ and analyzed with the Sparky program package ${ }^{[20]}$.

A reference spectrum was detected at thermal equilibrium with an HSQC pulse sequence with 100 real and 100 imaginary $t_{1}$ points $\left(\Delta t_{1}=280 \mu \mathrm{s}\right), \mathrm{pH}$ and temperature, but in a $90 \%$ protonated buffer and a recovery delay of $2 \mathrm{~s}$. The signals were averaged over 8 scans. The HSQC was detected in quadrature using the States-TPPI/PFG sensitivity-enhanced mode with carrier frequencies for ${ }^{1} \mathrm{H}^{\mathrm{N}}$ and ${ }^{15} \mathrm{~N}$ of 4.7 and $120.0 \mathrm{ppm}$, respectively. As in the HYPEX experiment, the Ubq concentration was ca. $1.05 \mathrm{mM}$.

A reference spectrum for determination of the enhancement factors $\varepsilon$ was acquired at thermal equilibrium immediately after the HYPEX experiment using the same sample and pulse sequence as the HYPEX spectrum but with 16 scans and $256 t_{1}$ increments.

The water-selective 2D NOESY-HSQC spectra started with a hard $90^{\circ}$ pulse, the water protons being selectively refocused by a gradient echo with a $20 \mathrm{~ms}$ sinc $180^{\circ}$ pulse at $4.7 \mathrm{ppm}$ sandwiched between two pulsed field gradients $(0.9 \mathrm{~ms}, 20 \mathrm{~T} / \mathrm{m})$, prior to flip-back and a mixing period $\tau_{\mathrm{m}}=0.3 \mathrm{~s}$. This interval allows the magnetization to migrate from $\mathrm{H}_{2} \mathrm{O}$ to the protein protons through a combination of cross-relaxation and chemical exchange. The excitation of ${ }^{1} \mathrm{H}^{\alpha}$ resonances was minimized by stepwise reducing the excitation bandwidth of the sinc $180^{\circ}$ pulse until no further reduction on the signal intensities $S_{\text {NOESY }}$ was observed, yielding a final pulse durations of $20 \mathrm{~ms}$.

For Relax EXSY ${ }^{15} \mathrm{~N}-T_{1}$ measurements were performed at 1 , 8,30 and $50 \%$ deuteration of the physiological saline buffer and fitted according to ref. ${ }^{[16]}$ to yield the H/D exchange constants.

Sample Preparation ${ }^{15} \mathrm{~N}$ enriched ubiquitin samples were produced by expression of the protein in $E$. coli BL-21-(DE3)pLysS in a minimal M9 medium containing $1 \mathrm{~g} / \mathrm{L}$ of ${ }^{15} \mathrm{~N}$ ammonium chloride as the only source of nitrogen. The protein was purified using ion exchange and gel filtration and finally transferred to a $99 \%$ deuterated buffer containing $137 \mathrm{mM} \mathrm{NaCl}, 2.7$ $\mathrm{mM} \mathrm{KCl}, 10 \mathrm{mM} \mathrm{Na}_{2} \mathrm{HPO}_{4}, 1.8 \mathrm{mM} \mathrm{KH}_{2} \mathrm{PO}_{4}$ and $5 \mathrm{mM}$ EDTA at $\mathrm{pH}$ 7.4.

\section{Acknowledgements}

Bruker BioSpin provided a prototype of a D-DNP polarizer. This work was supported by the French CNRS, the ERC (contracts 'dilute para water', grant agreement 339754 , and '2F4BIODYN', grant agreement 279519) and the Equipex 'Paris-en-Résonance', contract ANR-10-EQPX-09.

Keywords: Hyperpolarized Water - Dissolution DNP • Protein $\mathrm{NMR} \cdot$ Proton Exchange $\cdot \mathrm{NOE}$

[1] F. X. Theillet, A. Binolfi, B. Bekei, A. Martorana, H. M. Rose, M. Stuiver, S. Verzini, D. Lorenz, M. van Rossum, D. Goldfarb, P. Selenko, Nature 2016, 530, 45-50.

[2] D. H. Huberts, I. J. van der Klei, Biochim Biophys Acta 2010, 1803, 520-525.

[3] a) D. Kurzbach, W. Hassouneh, J. R. McDaniel, E. A. Jaumann, A. Chilkoti, D. Hinderberger, J Am Chem Soc 2013, 135, 11299-11308; b) L. Geist, M. A. Henen, S. Haiderer, T. C. Schwarz, D. Kurzbach, A. Zawadzka-Kazimierczuk, S. Saxena, S. Zerko, W. Kozminski, D. Hinderberger, R. Konrat, Protein Sci 2013, 22, 1196-1205; c) C. Gladkova, A. F. Schubert, J. L. Wagstaff, J. N. Pruneda, S. M. V. Freund, D. Komander, EMBO J 2017.

[4] a) S. Maekawa, H. Murofushi, S. Nakamura, J Biol Chem 1994, 269, 19462-19465; b) M. M. Babu, R. van der Lee, N. S. de Groot, J. Gsponer, Current Opinion in Structural Biology 2011, 21, 432-440.

[5] a) G. Olsen, E. Markhasin, O. Szekely, C Bretschneider, L. Frydman, J Magn Reson 2016, 264, 49-58; b) O. Szekely, G. L. Olsen, I. C. Felli, L. Frydman, Anal Chem 2018.

[6] D. Kurzbach, E. Canet, A. G. Flamm, A. Jhajharia, E. M. Weber, R. Konrat, G. Bodenhausen, Angew Chem Int Ed Engl 2017, 56, 389-392.

[7] J. Milani, B. Vuichoud, A. Bornet, P. Mieville, R. Mottier, S. Jannin, G. Bodenhausen, Rev Sci Instrum 2015, 86.

[8] P. Schanda, E. Kupce, B. Brutscher, J Biomol Nmr 2005, 33, 199-211.

[9] J. H. Ardenkjaer-Larsen, B. Fridlund, A. Gram, G. Hansson, L. Hansson, M. H. Lerche, R. Servin, M. Thaning, K. Golman, Proc Natl Acad Sci U S A 2003, 100, 10158-10163.

[10] L. Kay, E. P. Keifer, T. Saarinen, J. Am. Chem. Soc. 1994, 114, 10663-10665.

[11] P. K. Mandal, A. Majumdar, Concept Magn Reson A 2004, 20a, 1-23.

[12] J. Stonehouse, P. Adell, J. Keeler, A. J. Shaka, J. Am. Chem. Soc. 1994, 116, 6037-6038.

[13] N. V. Nucci, M. S. Pometun, A. J. Wand, Nat Struct Mol Biol 2011, 18, 245-249.

[14] B. Vuichoud, A. Bornet, F. d. Nanteuil, J. Milani, E. Canet, X. Ji, P. Miéville, E. Weber, D. Kurzbach, A. Flamm, R. Konrat, A. D. Gossert, S. Jannin, G. Bodenhausen, Chem Eur J 2016, 22, 14696-14700.

[15] L. Mueller, J Biomol NMR 2008, 42, 129-137.

[16] J. Lopez, P. Ahuja, I. Landrieu, F. X. Cantrelle, I. Huvent, G. Lippens, J Magn Reson 2014, 249, 3237. 
[17] J. Kim, M. Liu, C. Hilty, J Phys Chem B 2017, 121, 6492-6498.

[18] K. Wuthrich, G. Otting, E. Liepinsh, Faraday Discuss 1992, 35-45.

[19] F. Delaglio, S. Grzesiek, G. W. Vuister, G. Zhu, J. Pfeifer, A. Bax, J Biomol NMR 1995, 6, 277-293.
T. D. Goddard, D. G. Kneller, University of California, San Francisco, USA. 


\section{Entry for the Table of Contents}

Layout 2:

\section{COMMUNICATION}

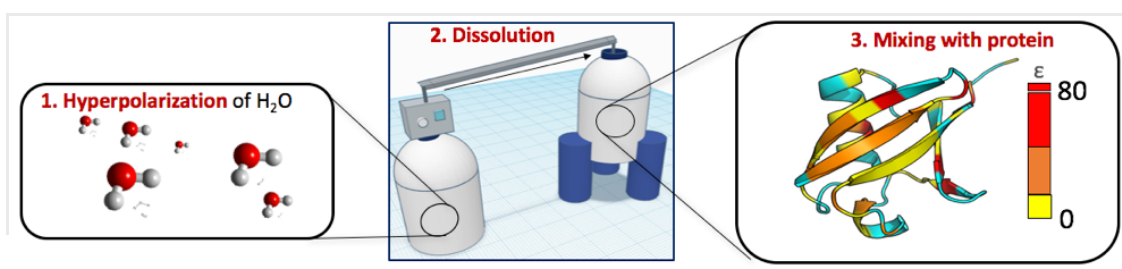

NMR of proteins under physiological conditions suffers from weak signal intensities. Hyperpolarization exchange spectroscopy overcomes this limitation by selectively enhancing residue-resolved NMR spectra of globular proteins by up to two orders of magnitude. The selective nature of the enhancements reflects the solvent interface of the target protein.
Pavel Kadeřávek ${ }^{[a], *}$, Fabien Ferrage ${ }^{[b]}$, Geoffrey Bodenhausen ${ }^{[b]}$, Dennis Kur$z_{b a c h}[b]$, *

Page No. - Page No.

High-Resolution NMR of Folded Proteins in Hyperpolarized Physiological Solvents 